\title{
A presença dos clássicos na arte escultórica de João Turin e a identidade paranaense
}

\section{Barbara Fonseca *}

DOI: 10.11606/issn.2318-8855.v9i1p268-288

Resumo: A partir das ideias do historiador britânico Martin Bernal, entendemos a presença do passado antigo nas políticas da modernidade e percebemos que esse é moldado conforme o seu momento histórico. Assim, notando a presença de elementos greco-romanos no Movimento Paranista, nos questionamos de que maneira a cultura clássica influenciou e foi usada na construção da identidade paranaense do início do século XX. Para tanto, analisamos a revista Illustração Paranaense, principal meio de comunicação entre a elite curitibana e destacamos João Turin como um dos principais artista do movimento, autor de obras em que se combinam os elementos paranaenses e greco-romanos. Dessa forma, no presente artigo, focamos na obra Columna Paranaense, criada por Turin, a fim de responder em que medida o uso da arte grecoromana em território paranaense serviu para exaltar o novo comportamento e a identidade paranista.

Palavras-chave: João Turin; Movimento Paranista; Paranismo; Usos do Passado

* 1 Graduada em História pela Universidade Federal do Paraná em 2019. Atualmente é mestranda pelo Programa de Pós-Graduação em História da UFPR e bolsista da CAPES. E-mail para contato: fonseca.bah@gmail.com. 


\section{artigos}

\section{A presença dos clássicos na arte escultórica de João Turin e a identidade \\ paranaense}

\section{Introdução}

Ao andarmos pelo centro de Curitiba notamos a presença de elementos da cultura greco-romana na cidade, como, por exemplo, no Prédio Histórico da Universidade Federal do Paraná (UFPR) - onde existem colunas gregas em sua fachada. Entretanto, muitas vezes, esses elementos não são percebidos por nós como arte greco-romana em um primeiro momento, pois se confundem com a arquitetura da cidade. Ou, são notados, mas não questionados. Dificilmente se pergunta o porquê da presença clássica combinada aos símbolos paranaenses. Renata Senna Garraffoni, entretanto, no texto “Reconfiguração dos estudos sobre a Antiguidade na atualidade: os desafios de novas abordagens", explica semelhantes questões ao entender que a manifestação de elementos clássicos no Paraná ultrapassa as barreiras decorativas, e constitui o que pode ser entendido por Usos do Passado (GARRAFFONI, 2014). Ou seja, o uso da cultura clássica para a constituição da cultura e identidade de uma sociedade em formação.

A partir desse entendimento, no esforço de ampliar o conhecimento da presença da cultura clássica no estado para além do exemplo do Prédio Histórico da UFPR, encontramos obras de João Turin em que se combinam os 'antigos' com os símbolos paranaenses. Grande parte dessas composições foi realizada durante o início do século XX, no intitulado Movimento Paranista. Conforme afirma Luís Afonso Salturi (2009), o Movimento Paranista foi uma maneira de colocar em prática o Paranismo, que por sua vez seria uma "forma de pensar" a identidade local do Paraná. Dessa maneira, o Movimento idealizado pela elite paranaense, mais especificamente a curitibana, 


\section{artigos}

Barbara Fonseca

buscou criar uma nova identidade para o estado, a qual tinha o intuito de construir uma nova cultura para a região que, naquele momento, não possuía expressão econômica em nível nacional.

João Turin fez uso da cultura greco-romana na criação de suas obras ao mesmo tempo em que participou da construção da identidade paranaense no início do século XX. Portanto, pensando nas razões dessa presença de elementos clássicos no estado; buscando o entendimento acerca do Movimento Paranista; e, da contribuição de Turin para a expressão desse movimento, foi desenvolvida durante 2017, com bolsa do CNPq por cinco meses, a iniciação científica de título "A criação da identidade paranaense: análise da recepção dos clássicos na arte de João Turin", a qual resultou no presente artigo. Nessa, delimitou-se como fonte da pesquisa a revista Illustração Paranaense, visto que tal periódico era o principal meio de comunicação da elite dirigente do estado e contaria como principal ilustrador João Turin. Ainda, a fim de reforçar nosso entendimento quanto à presença dos clássicos no Paraná, observamos excertos dos manuscritos de João Turin presentes no livro $A$ arte de João Turin, de Elisabete Turin (1998).

Dessa maneira o texto que se segue busca pensar como os clássicos estão presentes na modernidade e são usados para construir identidades, mais especificamente a paranista, assim, nos voltamos primeiramente aos estudos dos Usos do Passado, com os autores Martin Bernal, Pedro Paulo Funari, Renata Senna Garraffoni e Richard Hingley. Em seguida, entendemos o Movimento Paranista a partir de Luis Fernando Lopes Pereira e Luis Afonso Salturi. E, por fim, pensamos juntamente das fontes e de Elisabeth Turin, a presença dos clássicos da arte de João Turin, e como 


\section{artigos}

\section{A presença dos clássicos na arte escultórica de João Turin e a identidade}

paranaense

essa contribuiu para a expressão do Paranismo.

\section{A presença dos clássicos em cada momento histórico}

Entendemos que o conhecimento sobre o passado é inevitavelmente construído de acordo com as subjetividades de quem o molda, tanto a partir dos trabalhos historiográficos, quanto de documentos e visões elaboradas sobre um povo ou cidade a partir dela mesma. Como escreve Keith Jenkins, “o que é possível saber e como é possível saber interagem com o poder" (JENKINS, 2007: 31). Nesse sentido, entramos em contato com ideias e entendimentos acerca de uma sociedade que podem não ser totalmente condizentes com o período histórico dessa, mas com o que foi desejado que se acreditasse dele.

Uma vez que Martin Bernal (2005, p. 13-14) afirma que os Estudos Clássicos estão longe de ser isolados do resto da história, pois estes "teriam incorporado os padrões sociais e culturais dos contextos em que se desenvolveram", percebemos que nem mesmo o passado da antiguidade clássica, muitas vezes considerado estático, é capaz de fugir dos interesses de quem constrói o seu conhecimento. Por exemplo, notamos a partir dos escritos de Richard Hingley (2005) que os clássicos foram inseridos na história da Inglaterra Vitoriana como justificativa para a política imperialista de Estado. Afinal, os ingleses seriam descendentes de bretões e romanos e deveriam agir como tal, no caso, dominando outros territórios pelo mundo como o Império Romano fizera. Diante disso, observamos que a Roma Clássica serviu a muitos países europeus como matéria para a criação de identidades nacionais e mitos de origem. 


\section{artigos}

Barbara Fonseca

De maneira geral, ao ler Bernal e Hingley, percebemos que a antiguidade clássica foi pensada e usada de diversas formas para legitimação de políticas de governo. Contudo, é importante ressaltar que sociedades e países além do continente europeu também assimilaram elementos clássicos para a sua cultura. Como escreve Ricardo del Molino Garcia, durante o processo de independência colombiana, heróis grecoromanos foram propostos como modelos de excelência política a serem seguidos socialmente (GARCIA, 2009, p. 266). No caso brasileiro, para além dos exemplos apontados anteriormente, podemos notar a presença da cultura greco-romana também na construção da imagem da Primeira República, como dissertam Pedro Paulo Funari e Renata Senna Garraffoni acerca da representação dos bandeirantes paulistas. Essa representação ainda é, muitas vezes, entendida como verdadeira nos dias de hoje, sendo o bandeirante dotado do ideal do romano civilizador e conquistador, corajoso sem medo de desbravar os territórios desconhecidos (FUNARI; GARRAFFONI, 2012, p. 64). Funari e Garraffoni também apontam outros exemplos, como os elementos arquitetônicos clássicos misturados às cidades brasileiras, como o Museu Paulista e o Teatro de São Paulo.

Notamos a partir dos autores mencionados a presença frequente da cultura grega e romana nas nações e cidades modernas. A antiguidade não parece estar tão distante assim, e a visão que possuímos do passado em geral pode se alterar de acordo com o período que a pensa; entendemos a história além de apenas fatos concretos e objetivos. Portanto, retornando a questão inicial, percebemos que João Turin também utilizou os elementos clássicos em suas obras que expressavam os ideais paranistas. Nesse sentido, pensando na afirmação de Bernal de que o passado antigo está presente nas políticas da modernidade (BERNAL, 2005, p. 13 - 14), buscamos, nas seguintes páginas, discutir como os clássicos foram apresentados no Movimento 


\section{artigos}

\section{A presença dos clássicos na arte escultórica de João Turin e a identidade \\ paranaense}

Paranista.

\section{O Paraná no início do Século XX e o Movimento Paranista}

Entendemos que a construção da identidade paranaense no início do século XX foi realizada pelo Movimento Paranista, mas baseou-se ideologicamente no Paranismo, conforme afirmado no início do presente artigo. Apesar do Movimento Paranista ascender nos anos 1920, as ideias paranistas já circulavam no Paraná há pelo menos duas décadas. Para Salturi (2009, p. 19), “o Paranismo pode ser compreendido como um sentimento ligado a um ideal, uma 'forma de pensar' o Paraná relacionado à identidade local, seja ela na esfera política, econômica ou cultural, com vistas a um futuro próspero, rumo ao progresso". Dessa maneira, consideramos diversos artistas como paranistas, os quais não necessariamente concordaram ou fizeram parte de todo o Movimento.

Segundo afirmou Romário Martins (1948) o paranista poderia ser qualquer um que morasse no Paraná e trabalhasse para o seu crescimento, não importando se fosse imigrante, indígena, ou paranaense, desde que indicasse seu amor pela região. Contudo, analisando criticamente o Movimento, percebemos que por trás desse pensamento que buscava englobar todas as etnias em um sentimento de unidade, há a exclusão da presença dos negros, esquecidos e silenciados nessa nova identidade.

Conforme afirma Luís Fernando Lopes Pereira, "o fim da monarquia abre caminho para o sonho de uma nova sociedade" (PEREIRA, 1998, p. 19), pois se acentuou 


\section{artigos}

Barbara Fonseca

a política federalista e perdeu-se o símbolo centralizador do Imperador Dom Pedro II (PEREIRA, 1998. p. 52). Assim, a elite paranaense, positivista e anticlerical, que se desenvolveu a partir da intensificação do cultivo da erva-mate em fins do século XIX, demonstrou o anseio de construir um estado 'moderno' e homogêneo. Afinal, o Paraná era considerado até então uma região sem expressão nacional, sendo apenas um lugar de passagem entre Rio Grande do Sul e São Paulo (PEREIRA, 1998, p. 46).

Dessa maneira, a classe dirigente curitibana, a fim de alcançar a modernização, se volta aos "padrões europeus de civilidade", e realiza o esforço de ampliar a rede ferroviária, instalar a iluminação elétrica nos teatros e ruas, reformar a Universidade do Paraná, usar o sistema de tração elétrica nos bondes. Percebe-se, ainda, o número crescente de automóveis, o desenvolvimento da fotografia, no caso, das novas formas de registro e da indústria (PEREIRA, 1998, p. 57). Contudo, devemos ressaltar, como afirma Pereira, que esse "progresso" não ocorria de fato, sendo muitas vezes apenas reproduzido a partir de imagens, afinal, importaria apenas a potencialidade simbólica dessas (PEREIRA, 1998, p. 68).

Nas artes, por sua vez, os paranistas construíram símbolos e usaram da literatura e das artes plásticas a fim de fortalecer e legitimar sua nova identidade, sendo um dos principais símbolos o Pinheiro do Paraná. Conforme afirma Pereira (1998, p. 142), o pinheiro emergiu como máxima dos ideais paranistas e foi o alvo preferido dos artistas da época. A arte e o imaginário da população o enxergaram como ponto de apoio, pois supriu a necessidade de criar símbolos com raízes paranaenses, por ser nativo da flora do estado. Igualmente à árvore, o paranista do futuro seria pujante, de porte gigantesco. Todos seriam uma pinha que deveria florescer e dar origem a um novo 


\section{artigos}

\section{A presença dos clássicos na arte escultórica de João Turin e a identidade}

paranaense

pinheiro, assim, Pereira expressa que o pinheiro teria uma função pedagógica dentro dessa sociedade, afinal estaria presente em quase todos os quadros pintados no período, possuiria grande difusão nas artes plásticas e apareceria inúmeras vezes na revista Illustração Paranaense (PEREIRA, 1998, p.143).

O Movimento Paranista se destacou durante o período da Primeira República Brasileira e acabou perdendo força com a ascensão de Getúlio Vargas ao poder, em 1930, uma vez que Vargas adotou políticas que buscavam a centralização e a criação de uma identidade nacional, pondo em xeque, assim, os movimentos regionalistas. Entretanto, apesar do fim do Movimento, percebemos as ideias paranistas presentes até os dias de hoje no imaginário paranaense, como o símbolo do pinheiro e do pinhão.

\section{A revista Illustração Paranaense}

Um dos principais meios de comunicação social entre a elite, como já afirmado, foi a revista Illustração Paranaense. Essa foi publicada de novembro de 1927 a novembro de 1930 ininterruptamente, num total de 30 edições. Em 1933 houve, por fim, a publicação da $31^{\text {a }}$ edição. A revista apresentava reportagens do dia a dia e do lazer da elite paranaense, os principais eventos da cidade, contos sobre o estado e sobre os indígenas, fotos dos principais pontos curitibanos e de comemorações. Além disso, contava com diversas ilustrações dos artistas paranaenses e reportagens sobre esses, como de João Turin, o qual, segundo Luis Afonso Salturi, foi o principal ilustrador da revista, colaborando 57 vezes com desenhos presentes na revista. Além de Turin, Lange de Morretes e Artur Nísio também a ilustravam (SALTURI, 2014, p. 141). 


\section{artigos}

Barbara Fonseca

A revista foi criada pelo fotógrafo e jornalista João Baptista Groff, e, como afirma Geraldo Leão Veiga Camargo (2007: 171), foi pensada e produzida por um grupo vinculado aos círculos intelectuais que frequentavam o Clube Curitybano - espaço de reunião da elite paranaense. Turin foi ainda o autor de 29 das 31 capas das revistas, sendo essa sempre a ilustração do "Homem Pinheiro" - obra que se assemelha ao Homem Vitruviano - (Figura 1), alterando apenas a cor de fundo de acordo com a edição. Contudo, nas duas últimas revistas publicadas em 1930, a nº 9 e a n¹0 de 1930, a capa deixou de ser criada pelo artista e foi composta, respectivamente, por fotos do General Plinio Tourinho e de Getúlio Vargas. Retratando dessa maneira o período político vigente no país, e, por conseguinte, o enfraquecimento do Movimento Paranista.

Figura 1 - Homem Pinheiro. Revista Illustração Paranaense. Edição n¹, 1930 Fonte: Casa da Memória de Curitiba.

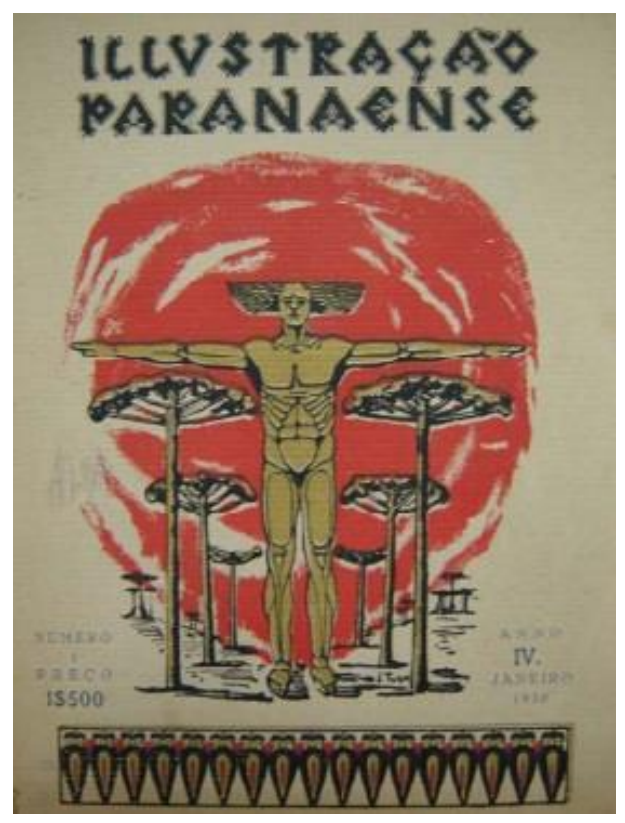

Para a realização da pesquisa, as 31 edições da revista foram encontradas na Casa da Memória de Curitiba e na Biblioteca Pública do Paraná. Analisamos as 31 edições e mapeamos a presença da arte greco-romana, a fim de entender a construção 


\section{artigos}

\section{A presença dos clássicos na arte escultórica de João Turin e a identidade}

paranaense

da identidade paranista. Também lemos a revista, com o intuito de entender mais sobre a elite curitibana e suas ações. Destacamos, então, as menções à cultura clássica que se misturam com os símbolos paranistas, e entre estas, encontramos principalmente as criações de João Turin.

\section{A Columna Paranaense e a presença dos clássicos na arte de João Turin}

Ao mapearmos a revista, encontramos como principal obra a Columna Paranaense, uma mistura da arquitetura da coluna grega jônica com o pinheiro do Paraná, permitindo-nos, assim, observar o uso da cultura clássica na construção da identidade paranista. Localizamos quatro menções a Columna Paranaense na revista. Primeiramente na edição n¹ de 1928 (figura 2), na página intitulada de "A estylisação Parananese". Há a ilustração junto da seguinte descrição: “Fragmentos inspirados em nossos magestosos [.sic] e imponentes pinheiros, pelo esculptor [.sic] J. Turim.". Encontramos a obra pela segunda vez na reportagem "O que pensa e o que disse $\mathrm{A}$ 'Senhorita Curityba' á 'Illustração Paranaense'", presente na edição n9 de 1928. Nessa, vemos uma foto (figura 3) da "Senhorita Curityba" junto com João Turin, no ateliê no próprio artista, observando a escultura da Columna Paranaense. 


\section{artigos}

Barbara Fonseca

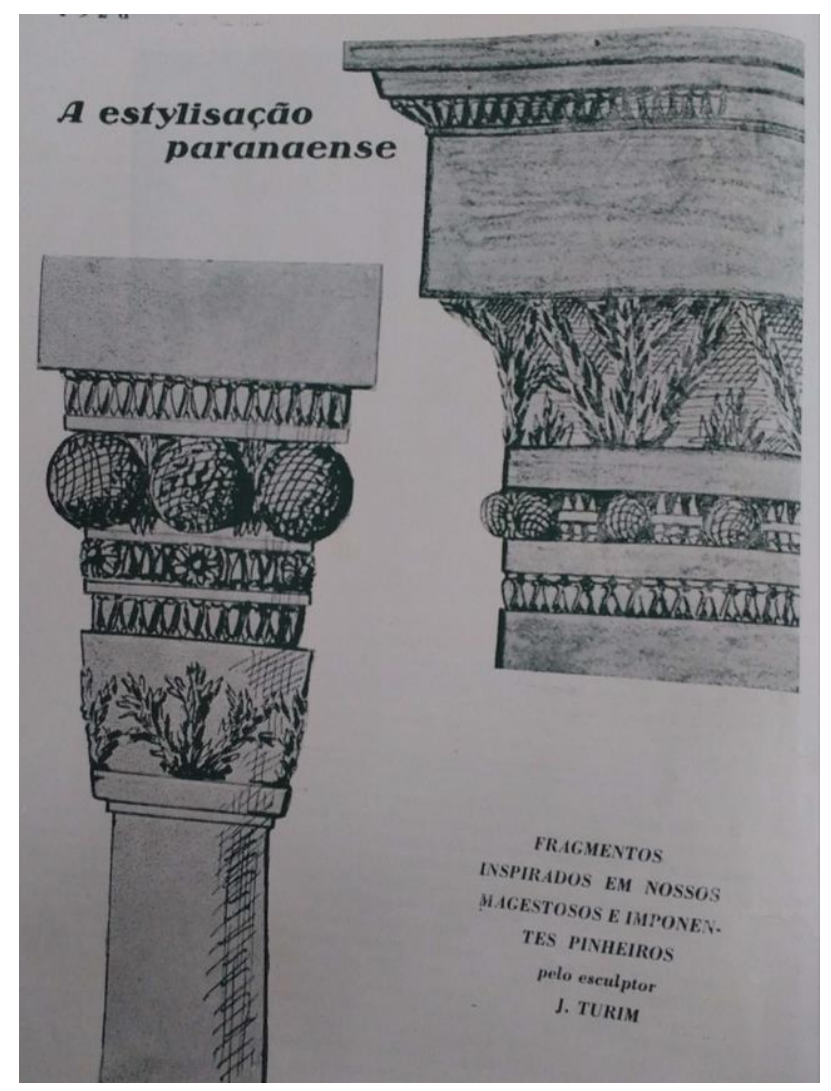

Figura 2 - Columna Paranaense. Revista Illustração Paranaense. Edição n¹, 1928 Fonte: Casa da Memória de Curitiba.

Por fim, existem duas menções à Columna na edição n 1 - 2 de 1929, em que se observa a presença mais enfática da obra criada por Turin na revista. Em primeiro momento, encontramos a matéria intitulada de "Columna Littoria e Columna Paranaense", de Amedeo Mammalella, em que se explora a relação entre a Columna Littoria (símbolo fascista) e a Paranaense, no esforço de explicar a obra criada por João Turin. Segundo Amedeo Mammalella:

Em Bolzano, a velha Bolgiano romantica, Marcello Piacentini, por suggestão do Duce, crea o monumento aos que tomaram, em robusto Templo quadrado, sustentado por columnas representando o Fascio Littorio; em Curityba João Turin concebe um novo typo de columna, inspirando-se na magestade e na belleza do característico pinheiro dos horizontes parananaenses. (MAMMALELLA, 1929)

Ainda no texto de Mammalella, percebemos de que maneira seria essa Columna 


\section{artigos}

\section{A presença dos clássicos na arte escultórica de João Turin e a identidade}

paranaense

criada por Turin; segundo o autor, essa possuía como característica principal “o capitel concebido como corôa de Pinhas, sobrepondo-se a um rico motivo sobre pinhões estylisados á maneira dos ovulos do estylo Jonico" (MAMMALELLA, 1929). Também conhecemos que para Mammalella, e, por conseguinte, para os paranistas, "a columna paranaense deverá conservar a elegancia da forma, afim de que a nova architectura que della florescerá contenha a expressão hieratia da planta que quasi se ergue para levar ao azul as aspirações da terra, a belleza sempre eterna da Esphera celestial" (MAMMALELLA, 1929). Demonstrando a grandeza desse símbolo para o estado, que em paralelo ao tamanho dos paranistas, seria altivo e comporia uma bela sociedade.

Figura 3 - João Turin em seu ateliê com a Senhorita Curityba observando a escultura da Columna paranaense. Revista Illustração Paranaense. Edição n9, 1928. Fonte: Casa da Memória de Curitiba.

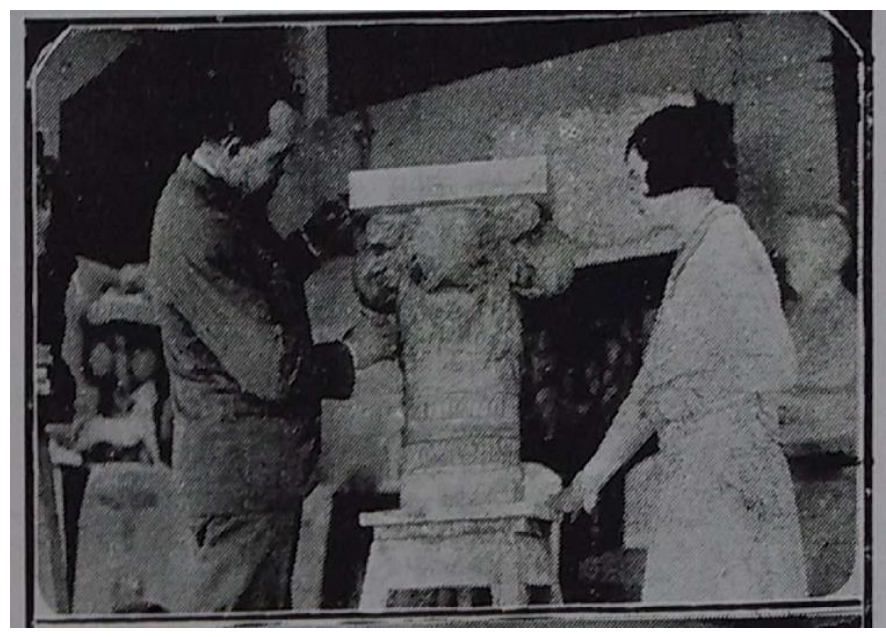

Finalmente percebemos a última aparição da Columna Paranaense, sendo essa como vinheta ilustrativa em uma reportagem acerca do Club Curitybano. Mais especificamente ao lado de uma foto da sessão magna do dia da posse da diretoria do Club, revelando a importância desse símbolo, visto que esse se faz presente ao lado da imagem da elite curitibana. Pensamos essa presença de maneira mútua, no caso, entendemos que a presença da Columna Paranaense junto da elite proporciona a noção 


\section{artigos}

Barbara Fonseca

de grandeza também para essa classe dirigente, ao passo que essa é vista ao lado do principal e célebre símbolo paranista: o pinheiro. Dessa maneira, após nos depararmos com esses exemplos, conhecemos a presença do elemento clássico na arte paranista e assim a sua importância. Afinal, a coluna se misturaria com o principal símbolo idealizado do movimento. Por outro lado, ainda nos restam perguntas: como podemos entender a relação da coluna com o pinheiro? Ou, mais especificamente, por que João Turin combinou ambos os elementos?

\section{João Turin, a Europa e a necessidade de inovar}

No início do século XX, João Turin foi estudar na Europa e após finalizar seus estudos em Bruxelas, foi à Itália, onde entrou em contato direto com a arte romana. Retornou ao Brasil em 1922. Segundo Elisabete Turin, o escultor realizou seu sonho de conhecer a arte clássica, desde as obras gregas, das romanas até as renascentistas e barrocas, e em doze dias visitou tudo o que havia de grande e belo em Roma. Como descreve a autora, o escultor percebia a arte clássica como grandiosa, e, para ele, o pinheiro também seria uma coluna maravilhosa, era necessário apenas orná-la com seus frutos e folhas para igualar-se em grandeza e beleza às colunas do Egito, Roma e Grécia antiga (TURIN, 1998, p. 122).

Contudo, conforme afirma Loio-Pérsio, apesar de João Turin considerar os artistas e as criações europeias fascinantes, procurou não os copiar, ilustrar e esculpir na nova arte paranista:

Turin aventurou-se na procura de um novo conteúdo, algo próprio de um povo e de uma terra diferente. Mas para isso seria necessário também uma nova forma, que se adequasse a tal conteúdo. Esse o problema com que se defrontou não só o velho Turin, mas todos os nossos artistas do começo do século, e com o qual se defronta ainda, embora de modo bem diferente, a maior parte dos artistas de hoje. (MAGALHÃES, 1998, p.163) 


\section{artigos}

\section{A presença dos clássicos na arte escultórica de João Turin e a identidade}

paranaense

Dessa maneira, entendemos que Turin buscava exaltar os elementos da flora paranaense, se diferenciando dos europeus afinal, como escreve o escultor, é necessário:

Decorar os templos, edifícios e moradas com criações inspiradas em nossa deslumbrante flora, é vivermos unidos com a beleza natural deste solo, que é a parte integral de nossa própria vida. Quebrar as correntes que nos retêm escravos do pensamento e da criação estrangeira, mostrar aos que nos visitam que também temos a liberdade de pensar e de plasmar o que sentimos como um povo livre. O povo que copia tudo o que é estrangeiro e se submete vergonhosamente à vontade de outros povos, sem ter a força de agir e de pensar por si próprio, é um povo escravo, que não pode ter o direito de se apresentar em uma assembleia de homens livres e civilizados.(TURIN apud MAGALHÃES, 1998, p. 164)

Nesse sentido, apesar da elite paranaense se espelhar na Europa para "renovar" Curitiba, o escultor acreditava que as criações europeias não deveriam ser repetidas no contexto paranaense, afinal, o Paraná seria rico em sua flora e possuiria uma terra fecunda e bela, capaz de proporcionar uma arte decorativa própria. Além de Turin, também haviam outros artistas que buscavam a exaltação da natureza e se distanciavam da ideia de progresso técnico europeu. A exemplo de Lange de Morretes, que incorporou em algumas de suas obras elementos clássicos e paranistas, como na pintura "A Alma da Floresta" (SALTURI, 2007, p. 173), na qual vemos uma Dríade deitada sobre o tronco cortado de uma Araucária. Dessa maneira, percebemos que as expressões artísticas durante a década de 1920 no Paraná não eram tão "rígidas" como talvez o Movimento Paranista gostaria de apresentar.

Cabe ressaltar que para nós talvez Turin se posicionar contra o europeu, mas admirar e emular as obras gregas e romanas antigas, seja uma contradição. Afinal, os povos antigos também se constituíram geograficamente na Europa. Contudo, para o 


\section{artigos}

Barbara Fonseca

escultor não havia incoerência, afinal os gregos e romanos antigos não eram os mesmos povos do continente europeu no período de vida de Turin.

Para Turin o que faltava em Curitiba era um arquiteto com audácia para construir essa nova arte baseada nas belezas regionais. (TURIN, 1998, p. 22). Conforme afirma o escultor:

Os nossos arquitetos vivem no meio dessa variedade de arbustos folhas e frutos tão belos, tão originais como foram as palmeiras e o lótus do Egito, como a folha de acanto da Grécia que se fez o famoso capitel coríntio, como o teto que os góticos ornavam as maravilhosas catedrais e não veem nada de interessante para estudar, para estilizar e aplicar em suas criações. [...] É incompreensível a falta de desejo de observação e de amor à terra nativa. Não se compreende que um artista possa viver escravo das criações dos outros povos e não aproveite a flora dessa terra fecunda, rica e bela. [...] (TURIN apud MAGALHÃES, 1998, p. 164)

Assim, ao entendermos a arte como importante instrumento de criação identitária, consideramos, igualmente a Pereira, que "a arte pode modificar as consciências e as pulsões dos homens" (PEREIRA, 1998, p. 137), e seria "exatamente neste sentido que a mesma [foi] utilizada pelos paranistas". Ou seja, usada para “modificar a consciência da heterogênea população que habitava as terras paranaenses", a fim de construir um sentimento de pertencimento ao Estado (PEREIRA, 1998, p. 137). No caso, criar a identidade paranista.

Dessa forma, compreendemos que ao relacionar a arte paranaense com a clássica, João Turin buscou exaltar e de certa maneira até mesmo legitimar a nova identidade paranaense, pois a coluna seria um elemento essencial da arquitetura antiga. Era grandiosa e bela, e servia de exemplo para os povos submissos da antiguidade:

O estilo paranaense tem por base o arbusto gigantesco que simboliza este solo maravilhoso onde nascemos. Os artistas egípcios, há sete mil anos eram menos 


\section{artigos}

\section{A presença dos clássicos na arte escultórica de João Turin e a identidade}

paranaense

escravos do que nós, cortaram as suas palmeiras e ornaram-na com o lótus e as folhas de papiro e colocaram-na nos seus templos. A coluna estava feita e devia servir de modelo a todos povos submissos da antiguidade, à força criadora daquele grande povo. Nós temos o pinheiro, essa coluna maravilhosa, só é necessário orná-la com seus frutos e folhas para igualar-se em grandeza e beleza às colunas do Egito, Roma e Grécia antiga. - Por que desprezamos? O que nos falta em Curitiba é um arquiteto com audácia. (TURIN apud MAGALHÃES, 1998, p. 164)

A composição de Columna Paranaense pode ser então, entendida como uma maneira de afirmar a grandeza do Paraná, pois ao comparar o símbolo máximo paranista com a arquitetura clássica, acaba por elevar a flora e a arte paranaense ao mesmo nível de beleza e grandeza da coluna jônica. Além disso, entendemos a possível relação entre a função da coluna na arquitetura e na construção da identidade, afinal a coluna alicerça o edifício e por consequência, o estado do Paraná.

Percebemos que a intenção de Turin em criar essa nova arte, apesar de destoar de desejos do Movimento Paranista ao criticar a simples cópia do que vinha da Europa, encaixa nos ideais do Paranismo, pois exalta o estado apresentando sua natureza, ao mesmo tempo em que a promove às "grandes" sociedades já desenvolvidas, no caso, Grécia e Roma. Dessa forma, identificamos as motivações da presença dos clássicos na arte de Turin, as quais seriam contribuir com o enaltecimento da nova cultura criada, a fim de dar destaque ao Paraná.

A presença desses elementos clássicos junto aos paranaenses foram importantes para a construção da identidade de um estado que não completava nem um século de independência, ao passo que a nova burguesia urbana e ligada à ervamate não enxergava grandes tradições e costumes do território. Portanto, a combinação grega, no caso da Coluna Jônica com a semente do pinheiro, dando origem 


\section{artigos}

Barbara Fonseca

à obra da Columna Paranaense, apresenta um dos caminhos percorridos para demonstrar a grandeza e a beleza do estado, na intenção de elevar o Paraná e a elite dirigente da região ao "nível" da sociedade grega, e colocar o Paraná entre um dos principais estados do país.

\section{Considerações finais}

Ao nos depararmos com a criação da Columna Paranaense por João Turin, ampliamos o conhecimento da presença greco-romana no Paraná e consequentemente com o campo de estudos de Usos do Passado no Brasil. Nesse sentido, enxergamos a revista Illustração Paranaense como uma importante fonte de pesquisa acerca da presença da cultura clássica no país, a qual pode e deve ser estudada mais afundo não apenas a partir da modernização de Curitiba, da exaltação da natureza e dos contos indígenas, mas também de acordo com as influências antigas presentes na identidade paranaense.

A partir da análise e leitura das fontes aqui apresentadas, juntamente com a bibliografia lida, percebemos a importância desses elementos clássicos para o período, bem como as motivações de seus usos dentro da sociedade paranaenses. João Turin foi um, entre vários artistas paranaenses, a combinar a antiguidade com os "novos" símbolos da região. Representando, dessa maneira, a grandeza do estado de maneira a qual essa não fosse ofuscada pela simples cópia de elementos europeus.

A combinação da coluna jônica ao pinhão, pode ser entendida, então, como intuito de demonstrar a imensidade dos símbolos paranistas, visto que a cultura grecoromana era e ainda é por alguns considerada grandiosa como uma das mais grandiosas do mundo ocidental. Nesse sentido, entendemos que os símbolos paranaenses eram colocados ao lado dos famosos elementos clássicos para serem 


\section{artigos}

A presença dos clássicos na arte escultórica de João Turin e a identidade paranaense

exaltados. Dessa maneira, Turin contribuiu para a construção da nova identidade paranaense expressa pelo Movimento Paranista ao elaborar novas possibilidades de enxergar as características originais, tradicionais e belas do estado.

Nesse sentido, percebemos certa pluralidade de obras e elementos no Paranismo e também no Movimento Paranista, observando que longe de apresentar apenas os ideais positivistas, anticlericais e republicanos que expunham a modernidade técnica e, consequentemente, a ideia de civilização. Existiam artistas empenhados em expressar diferentes ideias, que vão além da representação da natureza e chegam à antiguidade, mesmo que de maneira entrelaçada.

\section{Fontes}

Revista Illustração Paranaense. Edição no 1, 1928.

Revista Illustração Paranaense. Edição nº 9, 1928.

Revista Illustração Paranaense. Edição nº 1 - 2, 1929.

MAMMALELLA, Amedeo. In: Revista IIlustração Paranaense. Edição nº 1 - 2, 1929.

Manuscritos:

TURIN, João. Apud. MAGALHÃES, Loio-Pérsio. A dupla face de João Turin. In: TURIN, 


\section{artigos}

Barbara Fonseca

Elisabete. A arte de João Turin. Campo Largo: INGRA, 1998. p.164.

Referências bibliográficas

BERNAL, Martin. A imagem da Grécia Antiga como uma ferramenta para o colonialismo e para a hegemonia europeia. In: FUNARI, Pedro Paulo A. Coleção Textos Didáticos Repensando o mundo Antigo. IFHC-UNICAMP, n49, abril, p. 13 - 31, 2005.

CAMARGO, Geraldo Leão Veiga. Paranismo: arte, ideologia e relaçoes sociais no Paraná: 1853 - 1953. Tese de Doutorado - Universidade Federal do Paraná, Curitiba, 2007.

FUNARI, P.P.A.; GARRAFFONI, R.S. The Uses of Roman Heritage in Brazil: Traditional Reception and New Critical Approaches. In: Heritage \& Society. Volume 5, Issue 1, p. $53-76,2012$.

GARCIA, Ricardo Del Molino. Héroes antiguos para revoluciones modernas. La presencia de modelos grecorromanos de excelencia política em la independencia colombiana (1810 - 1816). In: Historia y Cultura: Congresos Comemorativos del Bicentenario de 1809. La Paz: Sociedad Boliviana de Historia, 2009.

GARRAFFONI, Renata Senna. Reconfiguração dos estudos sobre a Antiguidade na atualidade: os desafios de novas abordagens. In: SILVA, Helenice Rodrigues. Circulação das ideias e reconfiguração dos saberes. Blumenau: edifurb, 2014. pp. 77 - 91.

HINGLEY, Richard. Concepções de Roma: Uma perspectiva inglesa. In: FUNARI, Pedro Paulo A. Coleção Textos Didáticos IFHC-UNICAMP 2005. pp. 21 - 53.

JENKINS, Keith. A História Repensada. São Paulo: Contexto, 2007. 


\section{artigos}

A presença dos clássicos na arte escultórica de João Turin e a identidade paranaense

MAGALHÃES, Loio-Pérsio Navarro Vieira. A dupla face de Turin. In: TURIN, Elisabete. TURIN, A arte de João Turin. Campo Largo: INGRA, 1998. pp. 160 - 169.

MARTINS, Romário. Paranística. A divulgação, Curitiba, Ano I, n. 3-4, p. 37-39, fev./mar. 1948.

PEREIRA, Luis Fernando Lopes. Paranismo: o Parana inventado: Cultura e imaginario no Parana da I Republica. 2. ed. Curitiba: Aos Quatro Ventos, 1998

SALTURI, Luís Afonso. Frederico Lange de Morretes, liberdade dentro de limites: trajetória do artista-cientista. 268 f. Dissertação (Mestrado em Sociologia) - Setor de Ciências Humanas, Letras e Artes, Universidade Federal do Paraná, Curitiba, 2007.

SALTURI, Luís Afonso. Paranismo, movimento artístico do sul do Brasil no início do século XX. Perifèria. Revista d'investigació i formació en Antropologia, v. 11, n. 2, p. 71-92, 2009.

SALTURI, Luís Afonso. O movimento paranista e a revista Illustração Paranaense. Temáticas, Campinas, 22, (43): 127-158, fev./jun. 2014.

TURIN, Elisabete. A arte de João Turin. Campo Largo: INGRA, 1998.

Imagens

Figura 1 - Homem Pinheiro. Revista Illustração Paranaense. Edição n¹, 1930. Fonte: Casa da Memória de Curitiba.

Figura 2 - Columna Paranaense. Revista Illustração Paranaense. Edição n¹, 1928. Fonte: Casa da Memória de Curitiba. 


\section{artigos}

Barbara Fonseca

Figura 3 - João Turin em seu ateliê com a Senhorita Curityba observando a escultura da Columna paranaense. Revista Illustração Paranaense. Edição n9, 1928. Fonte: Casa da Memória de Curitiba. 